\title{
JOINING METHODS OF NATURAL SAUSAGE CASING WITH USING OF HIGH FREQUENCY CURRENT
}

\author{
Bartel S. ${ }^{*}$, Holek M. ${ }^{* *}$, Domin J. ${ }^{* * *}$, Karczewski J.**** , Kozielski L. ${ }^{* * * * *}$, \\ Pilch Z..***** , Wyciślok A."
}

\begin{abstract}
The article describes various joining methods of two natural casings pieces used in the sausage industry. It focuses on the use of high-frequency currents (HFCs) used in various areas of technology and medicine. Based on the experience of HFC applications in medicine, in the process of joining of living human body tissues during operations. Attempts have been made to use this method of joining in relation to extracted intestines in the process of obtaining natural casings for the sausage industry. The results of the experiments that were conducted are presented in the publication.
\end{abstract}

Keywords: Animal's intestines, Joining methods, High frequency current.

\section{Introduction}

Natural casing (NC) is a part of the animal intestine, small intestinal submucosa (SIS) - usually pork or sheep - obtained by mechanical separation from the intestine. SIS - an acellular, biological extracellular matrix (ECM) - is composed mainly of collagen fibers and contains elastin, glycosaminoglycans, proteoglycans (Shi et al., 2013) which preserving the mechanics of the living body tissue, that is used in food production is highly hydrated. Thickness of porcine SIS changes from $0.05 \mathrm{~mm}$ to $0.22 \mathrm{~mm}$, his surface have porous microstructure, with pores size changes from 20 to $30 \mu \mathrm{m}$ (Nihsen et al., 2008). SIS has a similar structure and biological properties to the skin. The tissues of the natural intestines are sensitive to temperature. The temperature below $40{ }^{\circ} \mathrm{C}$ does not change. The temperature above $40{ }^{\circ} \mathrm{C}$ to $60{ }^{\circ} \mathrm{C}$ causes hyperthermia, i.e. tissue stoppage, coagulation and permanent damage. The temperature above $60{ }^{\circ} \mathrm{C}$ causes devitalization - i.e. tissue death due to water evaporation. The temperature above $100^{\circ} \mathrm{C}$ leads to carbonization, i.e. tissue charring. The temperature above $300^{\circ} \mathrm{C}$ causes vaporization, i.e. tissue evaporation.

\section{Natural sausage casing joining methods}

Fig. 1 shows classification of the natural sausage casing joining method. There are three main types of natural casing combinations: electrical, luminous and biomechanics. Electrical methods of natural sausage casings joining are divided into:

- Resistance, where it can be noted by: joining of natural sausage casing (A), resistance wire (B) heating

MSc Eng. Cracow University of Technology, Faculty of Electrical and Computer Engineering, Warszawska Str. 24,

31155 Cracow, Poland, sebastian.bartel@doktorant.pk.edu.pl

** MSc Eng. Silesian University of Technology, Faculty of Mechanical Engineering, Konarskiego Str. 18A, 44100 Gliwice Mateusz.Holek@polsl.pl

*** PhD. Eng.: Silesian University of Technology, Faculty of Electrical Engineering, Akademicka Str., 44100 Gliwice, jaroslaw.domin@polsl.pl

**** PhD. Department of Biophysics and Plant Morphogenesis, University of Silesia, 40-032 Katowice, Poland; jerzy.karczewski@us.edu.pl

DSc PhD Eng. Faculty of Science and Technology, Żytnia Str. 12, 41200 Sosnowiec, lucjan.kozielski@us.edu.pl

PhD. Eng. Cracow University of Technology, Faculty of Electrical and Computer Engineering, Warszawska Str. 24, 31155 Cracow, Poland, zbigniew.pilch@pk.edu.pl

******* Eng.: MSc student, Faculty of Automatic Control, Electronics and Computer Science, Silesian University of Technology, Poland 
directly the intestines connected by the flowing current in the resistance wire. In this solution, the current flowing through the resistance wire can be stay or low frequency. An indirect method of joining natural casings will be the use of electrodes (B) with high frequency voltage for the outer part of the welded electrode. Due to the natural resistance of the intestines, there is a flow of high-frequency current and an increase in temperature, which causes the intestines to connect.

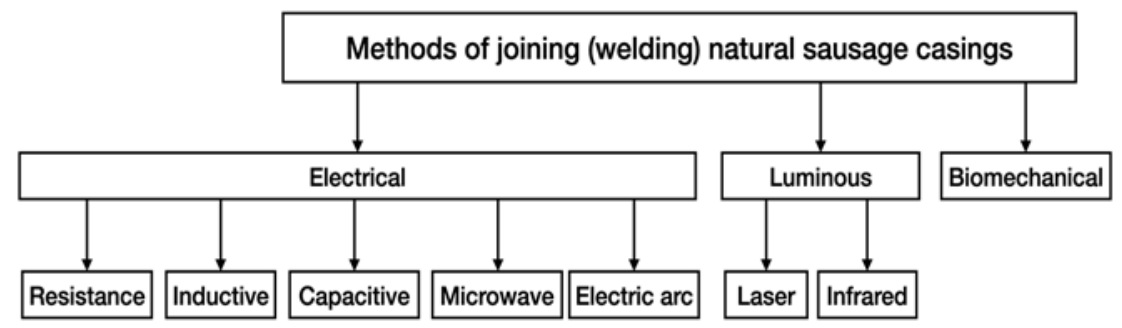

Fig. 1: Classification of the natural sausage casing joining method.

- Inductive, where this method is considered to be a non-contact welding of natural casings. The external emitter inductive electrode (C) where is powered with a frequency from several $\mathrm{Hz}$ to several tens of MHz. While the electrode (D) in which eddy currents are induced, they are generating the temperature rising and thus the way welding of the sausage casings have place.

- Capacitive, where the positive electrode is marked as (E), and the negative electrode as (F). Applied highfrequency voltage (from a few to several tens of $\mathrm{MHz}$ ) to the electrodes, causes a current flow in dielectric parts of natural sausage casing and thus generate the heat that joins the two pieces of casings.

- Microwave method, microwave emitter marked as (G) with emits an electromagnetic wave of the resonant frequency of water $(2.45 \mathrm{GHz})$ bringing the water molecules into vibrations that cause the temperature to rise, and thus joining two pieces of the natural sausage casings.

- The electric arc, it is a method of non-contact joining of natural casings through an electric arc in argon (I) atmosphere producing high temperature plasma.

a)

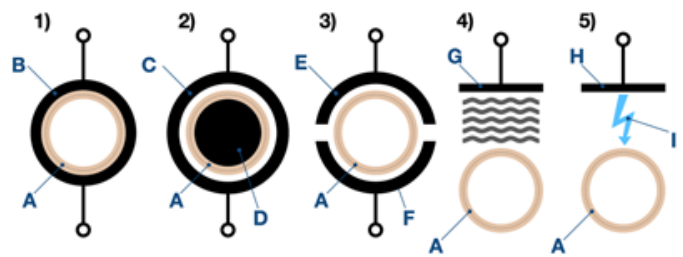

b)

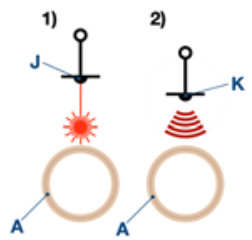

Fig. 2: Methods of joining intestines:

a) Electrical methods: 1) Resistance; 2) Inductive; 3) Capacitive; 4) Microwave; 5) An electric arc in an argon atmosphere; b) Luminous methods: 1) Laser; 2) Infrared light.

(A - Two layers of joined intestines; B - Resistance wire; $C$ - Induction heater coil; $D$ - Heating load for induction heater; $E$ and $F$ - Capacitive heater electrodes; $G$ - Microwave emitter; $H$ - The electric arc emitter; $J$ - Laser beam emitter; $K$ - Infrared light emitter.)

The above figure (Fig. 2b) shows two methods of luminous joining (welding) of the natural sausage casings. The first method is marked as (1), it is a method of joining natural casings using polarized laser light. The second method marked as (2) consists in joining the natural sausage casings using infrared light. Both of these methods produce a high temperature on the surface of the two intestines without contact, which causes them to join together.

Laser methods are used in medicine as high precision scalpels that give the advantage over knives that they clog up damaged blood vessels, significantly reducing bleeding. Lasers are also used to connect human body tissues. The bonding process can be realized without additional bonding agents, or with use of Some kind of binding glue. The publication (Ryabkin et al., 2017) describes research on the dependence of joined human body tissues, tensile strength, obtained at different temperatures, and denaturation of bovine serum albumin (the main component of laser welding). For medical applications it is important to choose the laser wavelength and exposure time (continuous or pulsed exposure). In order to obtain reliable joints, it is recommended to use solder based on bovine serum albumin (BSA) and multi-wall carbon nanotubes 
(MWNT) (Ryabkin et al., 2017). Laser radiation results in BSA denaturation. According to the authors, this is the main reason for the formation of joints on biological tissues. Nanotubes have a greater capacity to absorb laser beam. The presence of such nanotubes provides the basis for denatured albumin and can increase the strength of the resulting joint. The paper shows that reaching the temperature of $50-55{ }^{\circ} \mathrm{C}$ allows to obtain a connection with the highest mechanical strength.

\section{High frequency current welding (HFCW)}

Natural casings is characterized by a strong change of parameters depending on the origin of animals, time of breeding and slaughter. For example, the thickness of tissue can range from $0.05 \mathrm{~mm}$ to $0.22 \mathrm{~mm}$. The intestine is lining a single-layer cylindrical epithelium, the cells of this epithelium lie on the basement membrane, and it contains type four collagen. Due to its specific properties, non-toxicity and biocompatibility, collagen is used in medicine and cosmetology. Due to its high molecular weight, collagen does not penetrate through the skin and creates a hydrophilic filter layer (Zelaszczyk et al., 2012).

All mentioned features cause the process of joining (welding) the intestines to not be a repeatable process in every aspect, and it requires adjusting the process parameters to a given case. The first study involving the use of High frequency current was carried out using a SURTRON 200 surgical diathermy machine. Pig and sheep intestines were examined. In the process of joining, auxiliary agents (transglutaminase, albumin and $90 \%$ collagen solution) were used. The results of the tests are presented in Tabs. 1 and 2, where „P" means pork; „S” - sheep; „tran.” - transglutaminazie; „K-90” - kolagen 90 \%; ,albu.” - albumina.

Tab. 1: Results for joining of the casings with bayonet pliers.

\begin{tabular}{|c|c|c|c|c|c|c|c|c|c|c|c|c|c|}
\hline Intestines type & $\mathrm{P}$ & $\mathrm{P}$ & $\mathrm{P}$ & $\mathrm{S}$ & $\mathrm{S}$ & $\mathrm{P}$ & $\mathrm{P}$ & $\mathrm{S}$ & $\mathrm{S}$ & $\mathrm{P}$ & $\mathrm{P}$ & $\mathrm{S}$ & $\mathrm{S}$ \\
\hline Joining substance & - & tran. & tran. & tran. & tran. & $\mathrm{K}-90$ & $\mathrm{~K}-90$ & $\mathrm{~K}-90$ & $\mathrm{~K}-90$ & albu. & albu. & albu. & albu. \\
\hline Force [N] & 7.2 & 2.3 & 2.6 & 3.3 & 1.9 & 2.7 & 2.8 & 2.5 & 2.9 & 7.5 & 8.2 & 9.3 & 7.8 \\
\hline Strength [\%] & 24 & 8 & 9 & 11 & 6 & 9 & 9 & 8 & 10 & 25 & 27 & 31 & 26 \\
\hline
\end{tabular}

Tab. 2: Results for joining of the casings with ThermoStapler.

\begin{tabular}{|c|c|c|c|c|c|c|c|c|c|}
\hline Intestines type & $\mathrm{P}$ & $\mathrm{P}$ & $\mathrm{P}$ & $\mathrm{P}$ & $\mathrm{P}$ & $\mathrm{S}$ & $\mathrm{S}$ & $\mathrm{S}$ & $\mathrm{S}$ \\
\hline Joining substance & - & - & - & - & - & - & - & - & - \\
\hline Force [N] & 7.8 & 8.5 & 7.9 & 6.5 & 8.9 & 9.6 & 10.2 & 7.6 & 8.9 \\
\hline Strength [\%] & 26 & 28 & 26 & 22 & 30 & 32 & 34 & 25 & 30 \\
\hline
\end{tabular}

The obtained results are not satisfactory from the point of view of the requirements set (a repeatable result at the level of $70 \%$ of the strength of the proper intestine is required), but led towards building a custom welding head making use of these phenomena.

\subsection{Research workstation}

The stand for testing the possibility of connecting natural casings with the use of high-frequency currents, consisted of several components. Fig. 3 shows a block diagram of an intestine joining system making use of a high frequency current. The intestine welding head consists of 32 welding pins connected in four sets of eight pins. Each of the pins in the set is controlled independently, i.e. the signal from the high frequency current generator is redirected to individual pins via the current signal switcher.

The initial model of the welding head assumed the use of a set of 32 gold-plated pins supplying highfrequency current (from the potential side) in six sections of six pins activated sequentially. The metal lance

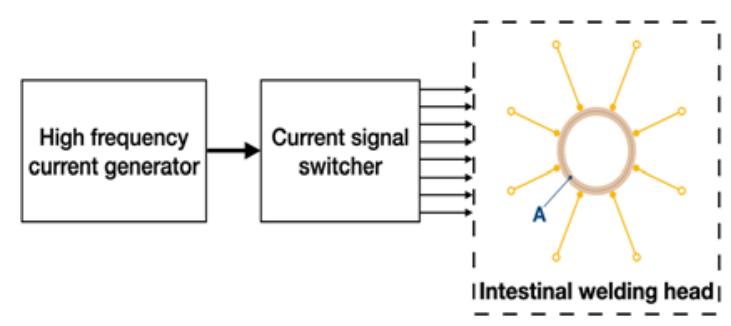

Fig. 3: The method of joining the intestines utilizing the high frequency current: A - Two layers of joined intestines. 
on which the intestines are stretched was responsible for the outflow of electricity (grounding). During the tests, it became apparent that the operation of such a system was not consistent with the assumptions. Not only the casings are not being welded, but there were no visible effects of the application of high-frequency current. Analysis of the problem indicated that the plausible cause was too wide grounding compared to the power level used, which, together with the moisture, resulted in the current having too many available paths to induce local effects.

\subsection{Measurement results}

A serious disadvantage of analyzed solution is that the electrodes interact with the intestine point-wise, which results in local carbonization or even vaporization of intestinal tissues. An example of the point-wise effect of the electrodes is shown in Fig. 4.

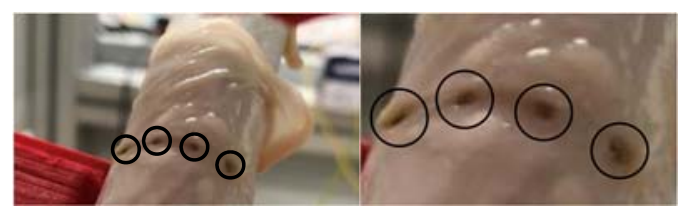

Fig. 4: Results of point-wise joining of natural casings by high-frequency current method.

Loss of intestinal integrity results in their tearing under relatively low loading forces. Consequentially, an attempt was made to modify the electrodes so that the area of their interaction with the surface of the intestines being joined. The introduced changes tested in the head, resulted in several welding attempts in which a joining zone between the casings was characterized by the breaking force of about $14 \mathrm{~N}$ (that is $70 \%$ of the average breaking force for the entire intestine), as per an ad hoc measurement with a force gauge. The persisting problem, however, was the lack of control over the course of the process, because, apart from the intestines with high breaking strength, most attempts ended with a complete failure - no connection of the casings or a partial failure - when the strength reached a force of $6-11 \mathrm{~N}$.

\section{Conclusions}

The conducted experimental studies related to the use of high frequency current welding (HFCW) gave ambiguous conclusions. On the one hand, the joints with immediate strength defined as about $70 \%$ of the strength of the uniform intestine were obtained, whereas on the other hand, the process was not unambiguously repeatable. This method has great potential for joining two sections of natural casings, but requires further research. The difficulty that needs to be overcome is the control over the parameters of the process (adaptive power selection, exposure time, humidity between the two intestines and between the intestine and the electrode, the width of the joint, the use of an appropriate connecting substance, etc.). The attractiveness of the method lies in the fact that, according to the authors, it is possible to obtain a connection that is fully durable and aesthetic for the recipient, over a relatively short section of the connection.

\section{Acknowledgement}

Presented findings are a result of a research project, conducted in JELUX Polska sp.z o.o., co-financed by NCBiR (nr umowy: POIR.01.01.01-00-0207/17-00).

\section{References}

Nihsen E.S., Johnson C.E. and Hiles M.C. (2008) Bioactivity of small intestinal submucosa and oxidized regenerated cellulose/collagen. Adv Skin Wound Care; 21: 479-86.

Ryabkin D. I. , Rimshan I. B., Gerasimenko A. Y., Pyankov, E. S. and Zar, V. V. (2017) Research of dependence of the laser weld tensile strength on the protein denaturation temperature, which is part of the solder, 2017 IEEE Conference of Russian Young Researchers in Electrical and Electronic Engineering (EIConRus), St. Petersburg, pp. 68-70, doi: 10.1109/EIConRus.2017.7910494.

Shi L., Ronfard V. (2013) Biochemical and biomechanical characterization of porcine small intestinal submucosa (SIS): a mini review. Int J Burn Trauma 2013; 3(4):173-179.

Zelaszczyk D., Waszkielewicz M. A., Marona H. (2012) Collagen - structure and application in cosmetology and aesthetic medicine. Estetologia Medyczna i Kosmetologia; 2(1): 14-20, doi:10.14320/EMK.2012.003 (in Polish). 